\title{
inu \\ Morphological and Allometric Changes in Anguilla japonica Larvae
}

\author{
Min-Gyu Shin ${ }^{1,2}{ }^{\oplus}$, Yong-Woon Ryu ${ }^{1}$, Youn-Hee Choi ${ }^{2,3, *}{ }^{1}$ and Shin-Kwon Kim ${ }^{1, *}$
}

1 Aquaculture Research Division, National Institute of Fisheries Science, 216, Gijanghaean-ro, Gijang-eup, Gijang-gun, Busan 46083, Korea; mingyushin7@gmail.com (M.-G.S.); ryuyw@korea.kr (Y.-W.R.)

2 Department of Fisheries Biology, Pukyong National University, Busan 48513, Korea

3 Department of Marine Bio-Materials \& Aquaculture, Pukyong National University, Busan 48513, Korea

* Correspondence: unichoi@pknu.ac.kr (Y.-H.C.); ksk4116@korea.kr (S.-K.K.); Tel.: +82-51-629-5915 (Y.-H.C.); +82-51-720-2421 (S.-K.K.)

check for updates

Citation: Shin, M.-G.; Ryu, Y.-W.; Choi, Y.-H.; Kim, S.-K. Morphological and Allometric Changes in Anguilla japonica Larvae. Biology 2022, 11, 407. https://doi.org/10.3390/

biology11030407

Academic Editor: Alberto Teodorico Correia

Received: 17 February 2022

Accepted: 4 March 2022

Published: 6 March 2022

Publisher's Note: MDPI stays neutral with regard to jurisdictional claims in published maps and institutional affiliations.

Copyright: (C) 2022 by the authors. Licensee MDPI, Basel, Switzerland. This article is an open access article distributed under the terms and conditions of the Creative Commons Attribution (CC BY) license (https:// creativecommons.org/licenses/by/ $4.0 /)$.
Simple Summary: The freshwater eel Anguilla japonica is a commercially important in Northeast Asia. However, eels farming is entirely dependent on natural catches, and eel resources are declining. This study was conducted to provide baseline information on the development of mass seed production technology necessary for the conservation of species and the maintenance of aquaculture. This study was conducted for 200 days after hatching (DAH) and analyzed morphometry and allometry. In this study, cultured eel larvae stages were divided in size similar to wild eel larvae, but cultured eel differed from wild eel in growth rate and the number of preanal myomeres. In addition, as eel larvae rarely have mixed feeding periods, it is important to determine the optimal first feeding time. The eel larvae may need a change in diet type to prevent lower jaw deformity in the leptocephalus stage. As eel larvae changed to a willow leaf-like form, the relative growth pattern of the eel larval stages was unique. This growth pattern may reflect the early life history of long distance and diel vertical migration. Meanwhile, the inflection point in the body parts' growth patterns showed only before $30 \mathrm{DAH}$ and was similar to the period of mass mortality. Therefore, future studies should focus on developing an optimal feeding and rearing protocol from the first feeding to $30 \mathrm{DAH}$.

Abstract: The freshwater eel Anguilla japonica is rapidly decreasing in number and has not yet been successfully mass produced. This may be at least partially attributable to the unique and long early life history of the eel. Therefore, we investigated its ontogeny of morphometry and growth pattern in larval stages to provide baseline information for understanding the early life history and improving seed rearing technology. This study was conducted for 200 days after hatching (DAH) and analyzed morphometry and allometry for eel larvae. The following cultured eel larval stages were identified: the yolk sac larvae stage (0-6 DAH, 3.23-6.85 $\mathrm{mm}$ total length (TL)), the pre-leptocephalus stage (7-30 DAH, 6.85-15.31 mm TL), and the leptocephalus stage (50-200 DAH, 15.31-60.06 mm TL). Cultured and wild eel larvae could be divided into characteristic larval stages at similar sizes. However, compared to wild eels, cultured eels had a slower growth rate and fewer preanal myomeres. Meanwhile, cultured eel larvae rarely had a mixed feeding period as the absorption of endogenous reserves was completed by $7 \mathrm{DAH}$. The lower jaw of eel larvae was significantly longer than the upper jaw from $50 \mathrm{DAH}$. In the pre-leptocephalus and leptocephalus stages, eel larvae showed continuous positive allometric growth at trunk height and tail muscle height with change to the willow leaf-like form. These growth characteristics may be the result of adaptation to the migration over long distances and to a diel vertical migration. The inflection point in the body parts growth patterns showed only before $30 \mathrm{DAH}$, and mass mortality appeared at this period. Therefore, to improve the growth and survival rates of cultured eel seed, it is necessary to focus on improving the feeding and rearing protocol until $30 \mathrm{DAH}$.

Keywords: ontogenetic development; leptocephalus; morphology; allometry; marine larviculture 


\section{Introduction}

The freshwater eel Anguilla japonica is a temperate catadromous fish distributed in the Philippines, Taiwan, China, Japan, and Korea [1-3]. This is a commercially important species in Northeast Asia, including Korea. However, eel aquaculture is dependent on the supply of seedlings (juveniles) through natural catches. The supply has been decreasing due to overfishing, habitat destruction, and changes in the marine environment [4]. Therefore, mass production of cultured seed is necessary to stabilize the eel aquaculture industry and preserve the species.

Research concerning cultured freshwater eel seed production began in the 1960s [5]. Yamamoto and Yamauchi [6] first succeeded in producing fertilized eggs using hormone treatments and reared larvae for up to five days after hatching (DAH). Tanaka et al. [7] later succeeded in growing larvae to the glass eel stage (seedling, juvenile), after which researchers succeeded in closing the eel life cycle by producing second-generation eels in 2010 [8-10]. However, artificial eel seed production was performed in laboratory-scale tanks and has not yet been developed on a commercial scale.

At present, due to the low production and high cost of cultured eel larvae in the laboratory, cultured eel seed is not used in the eel aquaculture industry [11]. The low production is due to slow growth by nutritional problems [11] and to a very low survival rate of less than 1\% [12]. Moreover, the high cost is caused by the time and labor costs of feeding at high frequencies and replacing rearing tanks every day due to the characteristics of the slurry type diet and the small scale rearing tank. Therefore, for efficient eel mass seed production, a rearing and feeding protocol optimized for eel larvae is required.

One of the major reasons for the difficulty in developing an optimized rearing method despite a long period of active research is related to the unique and long early life history of the freshwater eel. A. japonica inhabits freshwaters in Northeast Asia and migrates to the seamount of the West Mariana Ridge to spawn and hatch at depths of 150-200 m [13]. The eel larvae feed on marine snow (i.e., particulate organic matter, such as zooplankton fecal pellets and discarded larvacean houses) as a food source [14-16] and migrate to the Eddy region near Taiwan by the North Equatorial Current and the Kuroshio Current, where they metamorphose into the juvenile (glass eel) stage and migrate from the sea to rivers [17]. The period of metamorphosis from larva to juvenile occurs at 110-170 DAH in wild $[18,19]$ and at more than 200-250 DAH in culture [20]. Therefore, the freshwater eel differs from the early life history of common marine fish, and the details of its early life history remain to be elucidated.

For successful artificial seed production, it is important to develop an appropriate rearing protocol according to the developmental stage through understanding the early life history. In particular, the morphology during the larval stage can reflect the ecophysiology as a result of adaptation to the habitat. Fish larvae prioritize the growth of organs involved in primary functions (i.e., feeding, respiration, and locomotion) rather than organs with lower priorities for growth and survival, and the changes in body form occur due to the differential growth of organs [21,22]. Knowledge regarding these relative growth patterns during early development can contribute to larviculture by characterizing normal growth patterns under certain conditions and optimizing rearing protocols if abnormalities in larval development are detected [23-26]. Therefore, to improve the eel mass seed production technology, it is important to understand the growth characteristics of the larval stage in a culture environment.

There have been a number of previous studies on the morphology and growth characteristics of eel larvae. Mochioka [27] reported the morphology and growth characteristics of larvae from 10 to $60 \mathrm{~mm}$ in total length (TL) in wild. Although there have been many studies related to the morphology of eel larvae under culture conditions, such as the morphology and TL during 0-8 DAH [28], the morphology, TL, and preanal length during 0-15 DAH [29], the morphology, TL, head length, and trunk height during 0-100 DAH [30], the morphology during 100-270 DAH [7], the morphology during 0-268 DAH [31], TL and trunk height at 25 and $55 \mathrm{DAH}$ [32], TL during 0-80 DAH [11], distribution of TL at 
96 and 215 DAH [33], and the morphology, TL, and preanal length during metamorphosis [34-36], there have been no previous studies regarding morphological development and allometric growth patterns during long-term.

The aim of the present study was to describe the morphological development and allometric growth patterns for $A$. japonica larvae reared under culture conditions. In addition, we tried to confirm the growth characteristics of each larval stage and to understand the relationship between changes in allometric growth patterns and early mass mortality. Finally, we provided the basic data necessary to understand the early life history of $A$. japonica and to improve artificial seed rearing technology.

\section{Materials and Methods}

\subsection{Fish}

This study was conducted at the National Institute of Fisheries Science in Sirangri, Gijang-eup, Gijang-gun, Busan, South Korea. The rearing water was adjusted to the target temperature with a heat pump system (DHA-500-SLCF; Daeil Systems, Yongin-si, Gyeonggi-do, South Korea) after passing natural seawater through a high-pressure sand filter, ultraviolet filter, and 25- and 10- $\mu$ m cartridge filters. 28 female freshwater eels collected in September 2018 in Buan, Jeollanam-do, South Korea, and males reared in a fish farm for two years were used for seed production. Parental fishes were allowed to slowly acclimatize to the rearing water at $20^{\circ} \mathrm{C}$, with an increase of $5 \mathrm{psu} /$ day to $35 \mathrm{psu}$, for 1 week. For identification, microchips (Taechang, Seoul, South Korea) were inserted into the back muscles, and each fish was identified, tracked, and managed using a hand reader (RT160; Fofia, Wuxi, China). To induce maturity in parental fishes according to Kim et al. [29], 20 mg/fish of salmon pituitary extract (SPE; Yasaka, Abashiri, Hokkaido, Japan) were injected into the abdominal cavity of females weekly. A total of 24 females matured after an average of 7.92 weeks. For males, human chorionic gonadotropin (HCG; Daesung Microbiological Labs, Uiwang-si, Gyeonggi-do, South Korea) was injected into the abdominal cavity at $1 \mathrm{IU} / \mathrm{g}$ (body weight) for 12 weeks. Eggs were obtained by cannulation when the female body weight increased by $>20 \%$ compared to the initial body weight. When the diameter of the obtained eggs reached $>900 \mu \mathrm{m}$, maturity and ovulation were induced in females by injection of $10 \mathrm{mg} /$ fish of $17 \alpha$-hydroxyprogesterone (OHP; SigmaAldrich, St. Louis, MO, USA) and $10 \mathrm{mg}$ / fish of $17 \alpha, 20 \beta$-dihydroxy-4-pregnen-3-one (DHP; Sigma-Aldrich, St. Louis, MO, USA) into the abdominal cavity. Males were induced to ejaculate by abdominal compression, and sperm activity was checked using a ComputerAssisted Sperm Analysis (CASA) system (IVOS-II; Hamilton Throne Research, Beverly, MA, USA). The individual with the highest mean sperm activity was selected for breeding. Of the total 28 females, 17 females laid eggs, of which 10 batches hatched and only 7 batches survived until $7 \mathrm{DAH}$. Among them, 5 batches survived until an average of $37.8 \mathrm{DAH}$, and only 2 batches metamorphosed into glass eel. However, one batch could not be analyzed since only 20 larvae remained at $100 \mathrm{DAH}$. So, morphological and allometric changes were analyzed for one batch. As a result, to produce fertilized eggs, a mature female (initial $1042 \mathrm{~g}$ ) and the selected male (initial $187 \mathrm{~g}$ ) were combined in an ovulation induction tank with $20^{\circ} \mathrm{C}$ seawater at 17:00 on 26 December 2018, and the seawater was slowly warmed to $23^{\circ} \mathrm{C}$. At 09:00 on 27 December 2018, the naturally laid fertilized eggs were collected in an egg collection tank. The floating fertilized eggs were transported to an incubation tank at $23{ }^{\circ} \mathrm{C}$, gently aerated, and managed until hatching after approximately $48 \mathrm{~h}$.

\subsection{Larvae Rearing}

Hatched larvae were housed in a 500-L vertical cylindrical tank at approximately 500 individuals/L, and reared in running water at $23{ }^{\circ} \mathrm{C}$ supplied at $2 \mathrm{~L} / \mathrm{min}$ without feeding until 6 DAH. Eel larvae at 6 DAH were transferred to a 20-L round acrylic resin tank at approximately 100 individuals/L, and the first feeding was performed at $7 \mathrm{DAH}$ at 15:00. The feed based on the eggs of spiny dogfish consisted a slurry of soybean meal, fish meal, krill meal, and vitamins in accordance with the method established by Kim et al. [37] 
(Table 1). The water flow rate and feed viscosity were approximately $1.0 \mathrm{~L} / \mathrm{min}$ and $100 \mathrm{mPa} \cdot \mathrm{s}$ from 7 to $50 \mathrm{DAH}$, respectively. The feed $(6 \mathrm{~mL})$ was supplied five times daily $(09: 00,11: 00,13: 00,15: 00$, and 17:00) on the bottom of each tank. The water flow was stopped since eel larvae are not good swimmers when feeding. The water flow and feed viscosity were supplied at $1.0 \mathrm{~L} / \mathrm{min}$ and $100 \mathrm{mPa} \cdot \mathrm{s}$ on $7 \mathrm{DAH}$ and increased gradually to $1.5 \mathrm{~L} / \mathrm{min}$ and $200 \mathrm{mPa} \cdot \mathrm{s}$ on $200 \mathrm{DAH}$ with growth.

Table 1. Compositions of the slurry-type diets.

\begin{tabular}{ll}
\hline Ingredient & Diet \\
\hline Shark egg $^{1}(\mathrm{~g})$ & 50 \\
Fish soluble protein $^{2}(\mathrm{~g})$ & 3 \\
Soybean peptide $^{3}(\mathrm{~g})$ & 3 \\
Krill extract $^{4}(\mathrm{~g})$ & 6 \\
Vitamin mix $^{5}(\mathrm{~g})$ & 0.3 \\
\hline Proximate composition (mean $\pm \mathrm{SD}, n=5)$ \\
\hline Moisture $(\%)$ & $68.01 \pm 0.39$ \\
Crude protein $(\%)$ & $17.91 \pm 0.15$ \\
Crude lipid $(\%)$ & $10.42 \pm 0.21$ \\
Crude ash $(\%)$ & $0.73 \pm 0.03$
\end{tabular}

${ }^{1}$ Eggs of spiny dogfish (Squalus acanthias). ${ }^{2}$ Sopropeche. France. ${ }^{3}$ Shandong Yuxin Biotechnology. China. ${ }^{4}$ Krill $(5 \mathrm{~kg})$ was homogenized with distilled water $(4 \mathrm{~L})$ and incubated with a digestive enzyme mixture at $50{ }^{\circ} \mathrm{C}$ for $6 \mathrm{~h}$, and then, the mixture was filtered through a nylon plankton net (mesh opening, $100 \mu \mathrm{m}$ ), lyophilized at $-80^{\circ} \mathrm{C}$, and stored at $-50{ }^{\circ} \mathrm{C}$ until diet preparation. ${ }^{5}$ Vitamin mixture (per $1 \mathrm{~kg}$ dry matter): vitamin A, 5,000,000 IU; D3, 1,000,000 IU; E, 37,500 mg; K3, 2500 mg; C, 6400 mg; B1, 5000 mg; B2, 10,000 mg; B6, 5000 mg; B12, 25 mg; H, $50 \mathrm{mg}$; folic acid, $2500 \mathrm{mg}$; inositol, 75,000 mg; nicotinic acid, 37,500 mg; Ca-pantothenate, 17,500 mg. Diet viscosity was adjusted using sea water.

\subsection{Survival Rate}

To confirm the survival rate of eel larvae during ontogenesis, 500 eel larvae on 7 DAH were kept in eight 20-L round acrylic resin tanks. The rearing protocol was as described in Section 2.2 above. All eel larvae were counted at 15, 30, 50, 70, and 100 DAH. After keeping 28 larvae in 14 tanks on $100 \mathrm{DAH}$, all eel larvae were counted at 100, 125, 150, 175, and $200 \mathrm{DAH}$ to confirm the changes in survival rate over time.

\subsection{Sampling}

Eel larvae with no abnormalities (20 larvae $\times 18$ sampling points) were sampled at $0-7,10,15,30,50,70,100,125,150,175$, and 200 DAH (Figure 1). After anesthetizing with 200 ppm ethyl 3-aminobenzoate methane sulfonate (MS-222; Sigma-Aldrich, St. Louis, MO, USA), larvae during 0-50 DAH were photographed using a digital camera (AxioCam MRc5; Carl Zeiss, Oberkochen, Germany) connected to a stereomicroscope (SteREO Discovery V20; Carl Zeiss, Oberkochen, Germany), and larvae during 70-200 DAH were photographed using a digital camera (EOS 5D Mark II; Canon, Tokyo, Japan).

\subsection{Morphometric Analysis}

The TL, head length, head height, trunk length, trunk height, tail length, tail muscle height, digestive tract length (equal preanal length), digestive tract height, upper jaw length, lower jaw length, yolk sac area, oil globule area, and intestine area were measured on photographs of larvae using image analysis software (ZEN v. 2012; Carl Zeiss, Oberkochen, Germany) (Figure 2). 

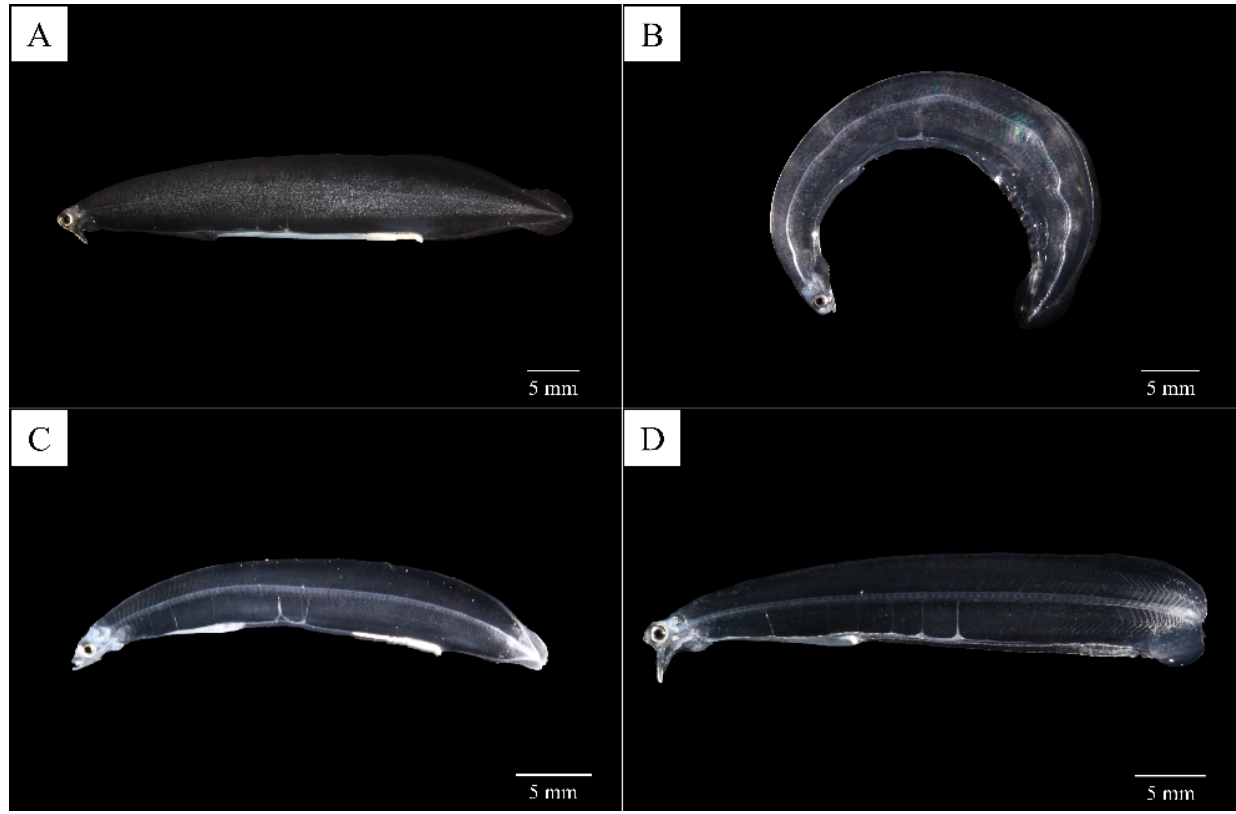

Figure 1. Abnormality of the Anguilla japonica in the leptocephalus stage in culture. (A) Posterior bent lower jaw. (B) Dorsal curvature of the notochord column. (C) Decayed tail fin. (D) Vertebrae compression and fusion of the tail region.

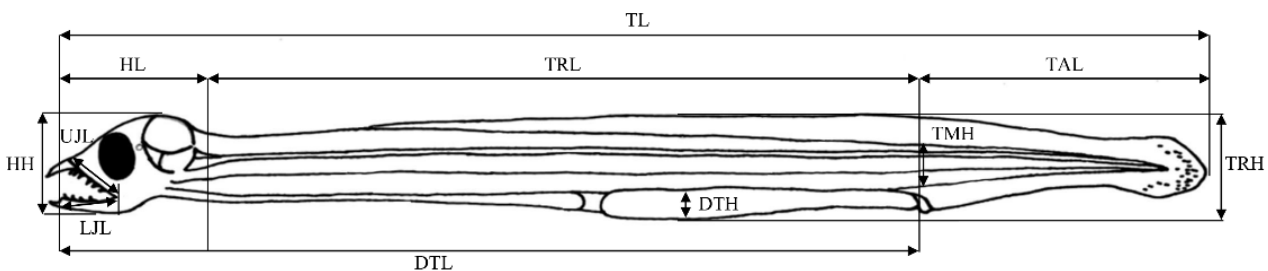

Figure 2. Morphometric measurements in Anguilla japonica larvae. Abbreviations: DTH, digestive tract height; DTL, digestive tract length; HH, head height; HL, head length; LJL, lower jaw length.; TAL, tail length; TL, total length; TMH, tail muscle height; TRH, trunk height; TRL, trunk length; UJL, upper jaw length.

\subsection{Allometric Analysis}

Allometric growth during the larval stages was calculated as a power function of TL, using the data of the measured morphometric characteristics with the following model:

$$
y=a x^{b}
$$

where $y$ is the measured character, $a$ is the intercept, $x$ is the TL, and $b$ is the growth coefficient [21]. With regard to the specific morphological characteristics, the height was compared with TL and isometric growth was determined when $b=1$ for length. Positive allometric growth was determined when $b>1$, corresponding to a higher growth rate than TL, while negative allometric growth was determined when $b<1$. Linear regression analysis was performed on the $\log$ transformed data according to $\log y=\log a+b \log x$ [38]. Regression lines were calculated for $x_{\min }$ to $x_{\text {intermediate, }}$ and for $x_{\text {intermediate }}$ to $x_{\max }$ and the growth coefficients from both linear regression equations were compared using the $t$ test $(p<0.01)$ [39]. The inflection point was calculated as $x_{\text {intermediate }}$ when it showed the largest $t$ value and the regression lines had $p<0.05$.

\subsection{Statistical Analysis}

Data are shown as the mean \pm standard deviation (SD). Potential differences in yolk sac area and oil globule area were tested by one-way analysis of variance (ANOVA). 
The null hypothesis is that there are no differences among 0-7 DAH. When a significant difference was found, Tukey's honestly significant difference (HSD) test was performed. An independent two-sample $t$ test was performed to compare the mean values between upper jaw length and lower jaw length. The null hypothesis is that there are no differences between upper jaw length and lower jaw length. In all analyses, $p<0.05$ was taken to indicate statistical significance. Statistical analyses were performed and graphics were prepared using SPSS software, version 25 (IBM, Armonk, NY, USA) and Excel 2016 software (Microsoft, Redmond, WA, USA).

\section{Results}

\subsection{Identification of Larval Stages}

In this study, the initial average size of A. japonica larvae was $3.58 \pm 0.15 \mathrm{~mm} \mathrm{TL}$ and increased following TL $=0.2419 \mathrm{DAH}+5.016\left(\mathrm{R}^{2}=0.99\right)$, reaching $52.66 \pm 4.26 \mathrm{~mm}$ at $200 \mathrm{DAH}$. According to the morphological criteria of wild eel larvae reported previously [27], the eel larval stages under culture conditions were characterized as follows: yolk sac larval stage (from after hatching until the presence of endogenous reserves), preleptocephalus stage (needle-like teeth, the anus has moved to the posterior of the body, and the number of preanal myomeres has increased), and leptocephalus stage (teeth replaced by regular broad-based teeth, the position of the anus remains stable). According to the morphological criteria, the yolk sac larval stage was from 0 to $6 \mathrm{DAH}$, pre-leptocephalus stage was from 7 to $30 \mathrm{DAH}$, and leptocephalus stage was from 50 to $200 \mathrm{DAH}$. To separate the eel larval stages by TL, yolk sac larvae stage and pre-leptocephalus stage were divided by the average TL between $6 \mathrm{DAH}(6.59 \mathrm{~mm})$ and $7 \mathrm{DAH}(7.10 \mathrm{~mm})$, and pre-leptocephalus stage and leptocephalus stage were divided by the average TL between $30 \mathrm{DAH}(12.77 \mathrm{~mm})$ and $50 \mathrm{DAH}(17.86 \mathrm{~mm})$. The TL of the characterized larval stages were as follows: yolk sac larvae stage (larval stage I: 0-6 DAH, 3.23-6.85 mm TL), pre-leptocephalus stage (stage II: 7-30 DAH, 6.85-15.31 mm TL), and leptocephalus stage (stage III: 50-200 DAH, 15.31-60.06 mm TL) (Figure 3).

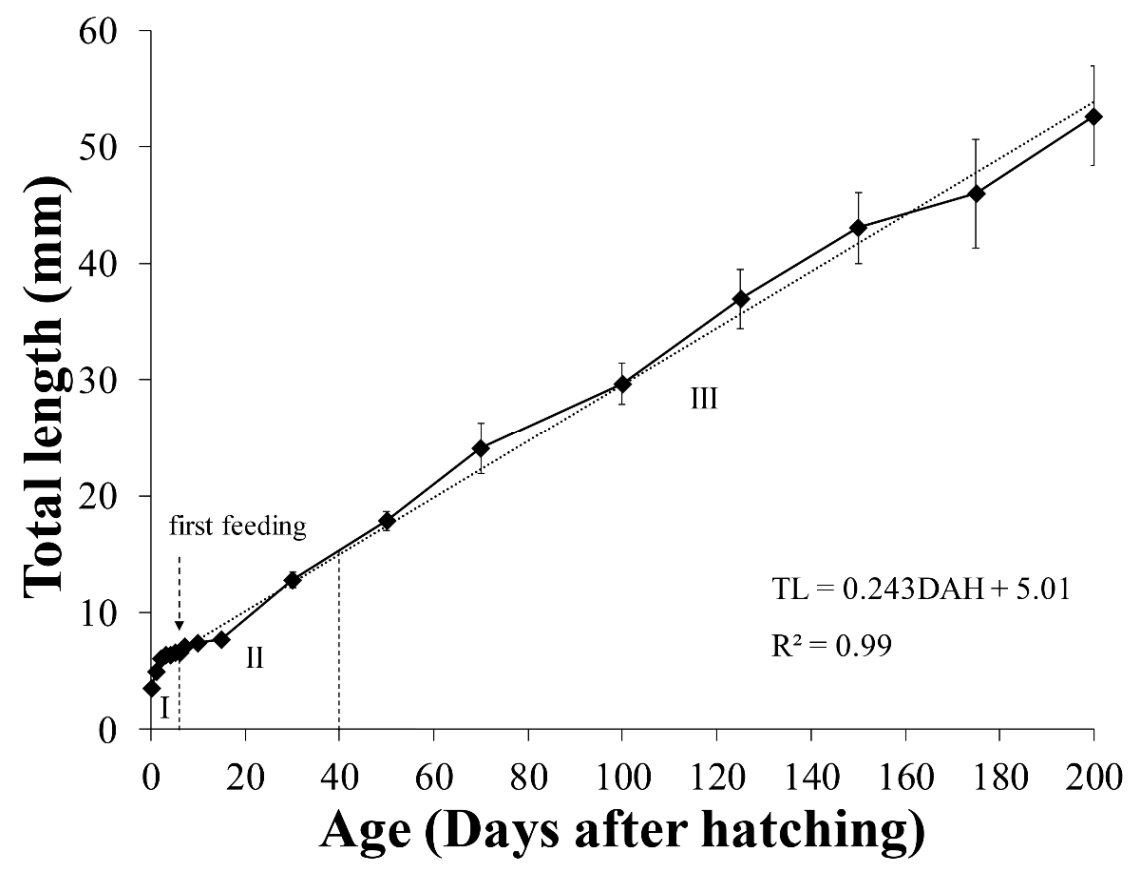

Figure 3. Growth of total length in Anguilla japonica from 0 to 200 DAH (stage I: yolk sac larvae; stage II: pre-leptocephalus; stage III: leptocephalus). Values are means \pm SD. Abbreviations: DAH, days after hatching; TL: total length. 


\subsection{Survival Rate}

The survival rate of eel larvae decreased sharply after the first feeding. The survival rate at $15 \mathrm{DAH}$ was $43.70 \pm 14.15 \%$. The highest mortality rate was recorded at this time point, which was determined to be critical period I. The survival rate at $30 \mathrm{DAH}$ was $15.60 \pm 8.66 \%$, and the second highest mortality rate was recorded at this time point, which was determined to be critical period II. The survival rate continued to decrease during $50-200 \mathrm{DAH}(7.78 \pm 4.44 \%$ at $50 \mathrm{DAH}, 2.48 \pm 2.18 \%$ at $100 \mathrm{DAH}, 1.30 \pm 0.54 \%$ at $150 \mathrm{DAH}$, and $0.79 \pm 0.50 \%$ at $200 \mathrm{DAH})$. Statistical analysis was not performed on the survival data since the number of specimens decreased during the experiment rearing (Figure 4).

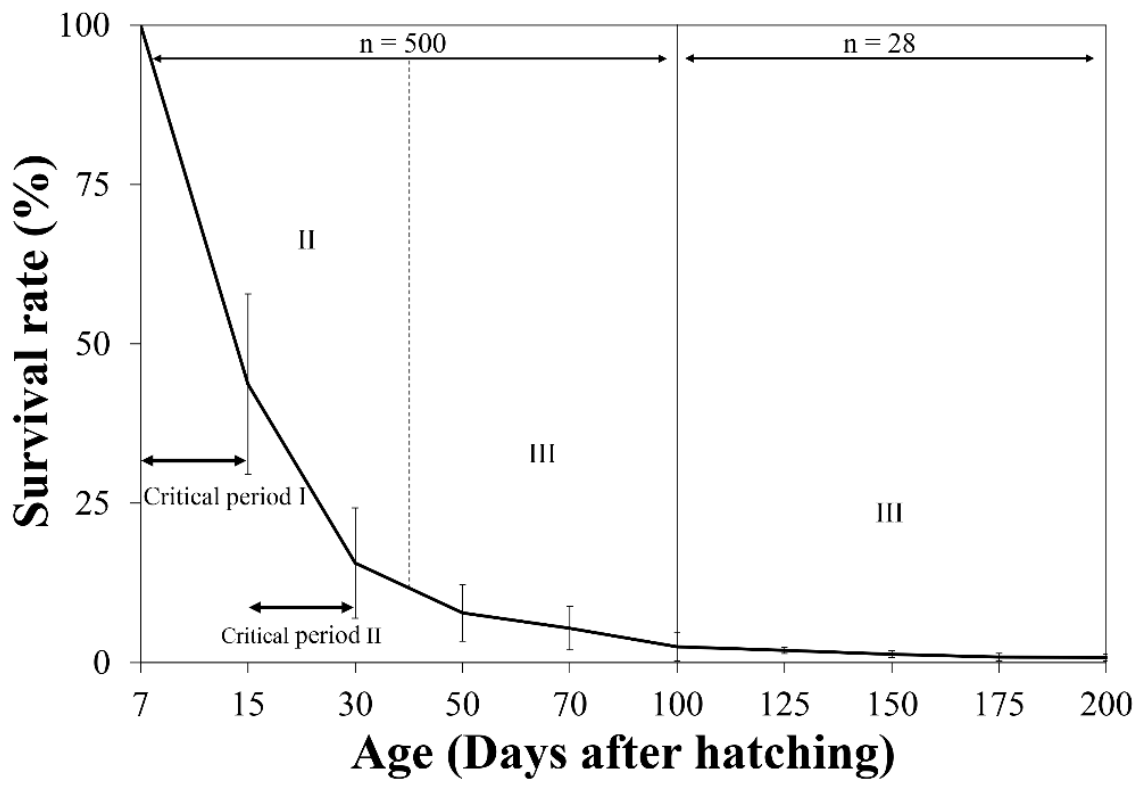

Figure 4. Survival rates of Anguilla japonica larvae during three larval stages from 7 to $200 \mathrm{DAH}$. Values are means \pm SD. Abbreviations: DAH, days after hatching; II, stage II (pre-leptocephalus stage); III, stage III (leptocephalus stage).

\subsection{Morphological Development}

3.3.1. Yolk Sac Larvae (Stage I; 0-6 DAH)

At hatching, the average TL of $A$. japonica larvae was $3.58 \pm 0.15 \mathrm{~mm}$, and the larvae had a large yolk sac (area $=0.691 \pm 0.057 \mathrm{~mm}^{2}$ ) containing one oil globule ( area $=0.086 \pm 0.004 \mathrm{~mm}^{2}$ ) in the lower anterior part. The body was transparent, and several melanophores were observed at the end of the notochord. At $1 \mathrm{DAH}$, the average TL was $5.01 \pm 0.20 \mathrm{~mm}$, the oil globule was pushed back as the front yolk sac was absorbed, and a yolk syncytial layer appeared at the point of yolk absorption. Melanophores moved to the tip of the caudal fin. At $3 \mathrm{DAH}$, the average TL was $6.41 \pm 0.21 \mathrm{~mm}$, the mouth and anus were open, and a straight digestive tract was observed along the notochord. The area of the yolk sac decreased significantly until $4 \mathrm{DAH}$, when the body changed into a slender type. At $5 \mathrm{DAH}$, the average TL of $A$. japonica larvae was $6.65 \pm 0.21 \mathrm{~mm}$, and a canineshaped front tooth appeared. There were no significant differences in length between the upper and lower jaws before $5 \mathrm{DAH}(p>0.05)$, but at $5 \mathrm{DAH}$, significant differences began to be observed between the upper jaw length $(0.151 \pm 0.017 \mathrm{~mm})$ and lower jaw length $(0.195 \pm 0.026 \mathrm{~mm})(p<0.05)$. At $6 \mathrm{DAH}$, the average TL was $6.59 \pm 0.18 \mathrm{~mm}$, the eyes were darkly pigmented, and more melanophores were observed at the tip of the caudal fin with growth. The angle of the anterior tip of the upper jaw to the esophagus was approximately $160^{\circ}$ and was turned downward, and a number of needle-like teeth were observed. There was a significant difference between upper jaw length $(0.310 \pm 0.019 \mathrm{~mm})$ and lower jaw length $(0.265 \pm 0.022 \mathrm{~mm})(p<0.05)$. The average the yolk area was $0.036 \pm 0.013 \mathrm{~mm}^{2}$, and a significant difference was confirmed at $5 \mathrm{DAH}\left(0.087 \pm 0.027 \mathrm{~mm}^{2}\right)(p<0.05)$. How- 
ever, there was no significant difference in the average yolk area between 6 and $7 \mathrm{DAH}$ $\left(0.029 \pm 0.016 \mathrm{~mm}^{2}\right)(p>0.05)$, so absorption of the yolk sac was determined to be complete at $6 \mathrm{DAH}$. The oil globule was mostly absorbed at $7 \mathrm{DAH}\left(0.002 \pm 0.002 \mathrm{~mm}^{2}\right)$, so the completion of oil globule absorption was also determined to be at 6 DAH. Therefore, the yolk sac larval stage was characterized by completion of the absorption of endogenous reserves (Figures 3, 5A, 6 and 7).
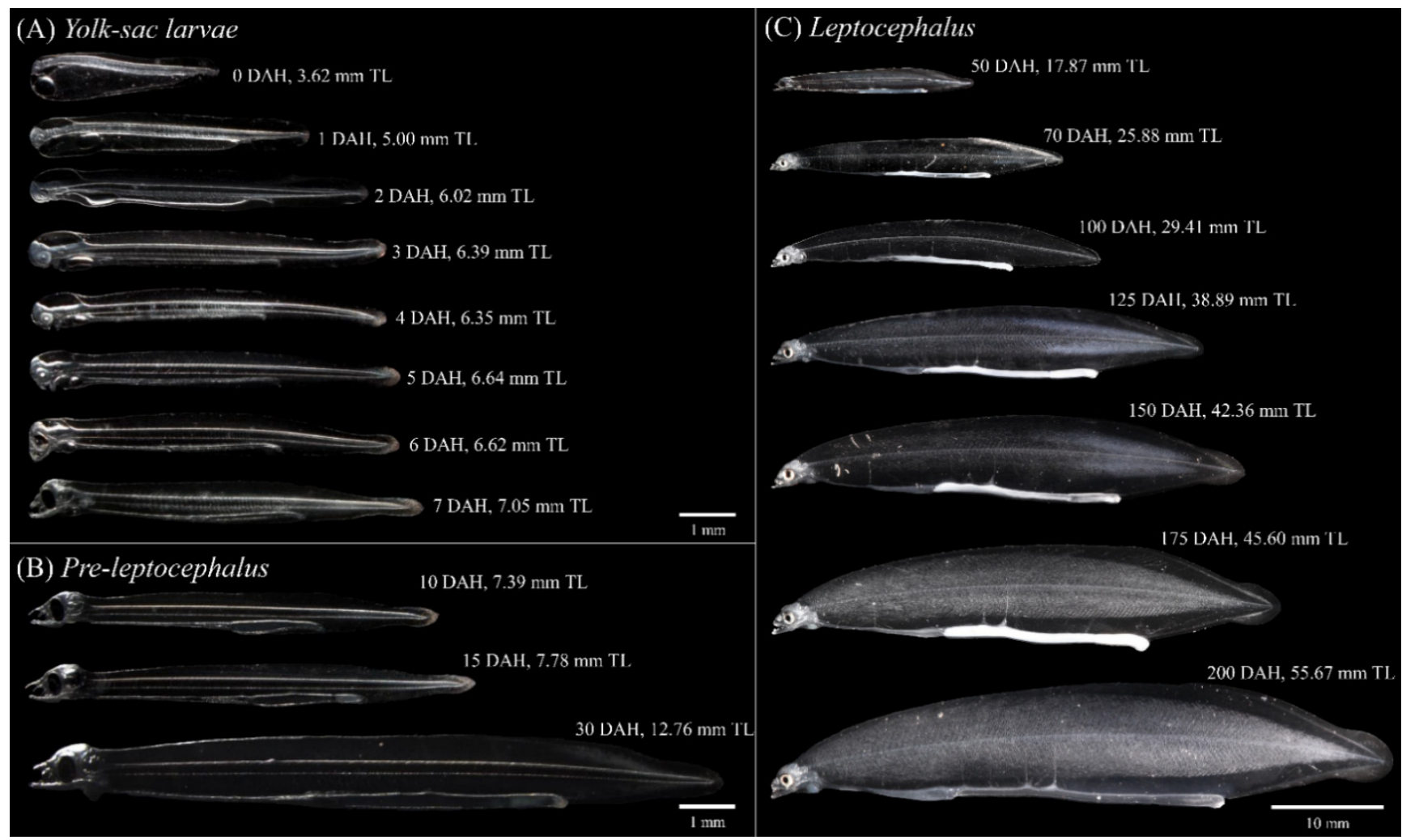

Figure 5. Morphological development in early ontogeny of Anguilla japonica larvae. (A) Yolk sac larval stage. (B) Pre-leptocephalus stage. (C) Leptocephalus stage. Abbreviations: DAH, days after hatching; TL, total length.

\subsubsection{Pre-Leptocephalus (Stage II; $7-40 \mathrm{DAH}$ )}

At $7 \mathrm{DAH}$, the average TL was $7.10 \pm 0.25 \mathrm{~mm}$, and lower jaw length $(0.407 \pm 0.021 \mathrm{~mm})$ was significantly longer than the upper jaw length $(0.394 \pm 0.024 \mathrm{~mm})(p<0.05)$. With growth of the lower jaw, the angle of the anterior tip of the upper jaw to the esophagus became parallel to approximately $180^{\circ}$, and eel larvae began exogenous feeding. Melanophores increased in number at the tip of the caudal fin, and the eyes became darker with more pigmentation. Digestive tract length (preanal length) was $4.93 \pm 0.15 \mathrm{~mm}$, and the anus was located at $69.4 \%$ of the body length. At $15 \mathrm{DAH}$, the average TL was $7.73 \pm 0.43 \mathrm{~mm}$, and the lower jaw length $(0.460 \pm 0.049 \mathrm{~mm})$ remained significantly longer than the upper jaw length $(0.417 \pm 0.035 \mathrm{~mm})(p<0.05)$. In addition, the rectum valve developed and began to differentiate between the intestine and the rectum. Digestive tract length (preanal length) was $5.84 \pm 0.30 \mathrm{~mm}$, and the anus was located at $75.5 \%$ of the body length, and the number of preanal myomeres was 59-61 $(n=5)$. At $30 \mathrm{DAH}$, the average TL was $12.77 \pm 0.66 \mathrm{~mm}$, and the needle-like teeth had decreased in size. There was no significant difference between upper jaw length $(0.597 \pm 0.034 \mathrm{~mm})$ and lower jaw length $(0.600 \pm 0.044 \mathrm{~mm})(p>0.05)$. A small number of melanophores were present at the tip of the caudal fin. Digestive tract length (preanal length) was $10.15 \pm 0.54 \mathrm{~mm}$, and the anus was located at $79.5 \%$ of the body length. The number of preanal myomeres was 63-71 $(n=5)$, which had increased from $15 \mathrm{DAH}$. Therefore, the pre-leptocephalus stage was 
characterized by needle-like teeth and an increase in number of preanal myomeres with the anus moved to the posterior of the body (Figures 3, 5B and 7).

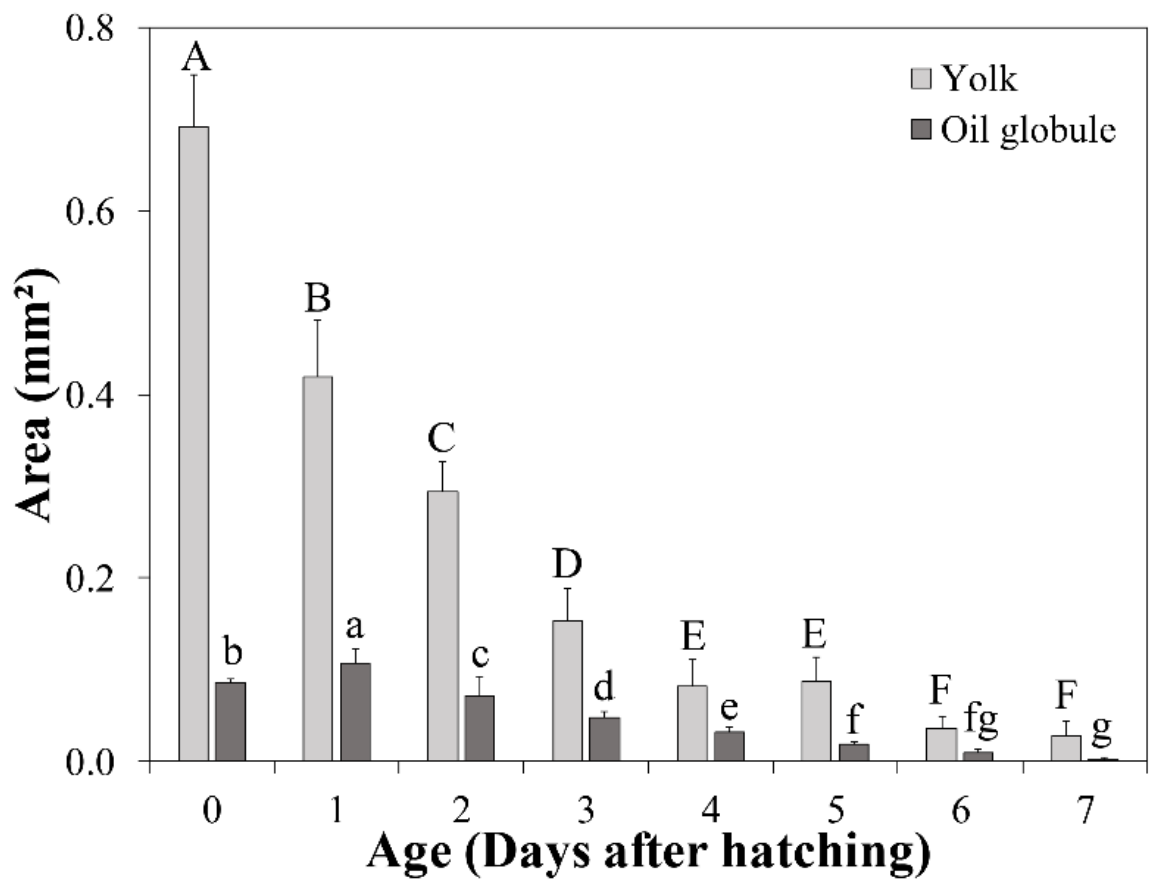

Figure 6. Yolk sac and oil globule utilization in Anguilla japonica larvae. Values are means \pm SD. Different uppercase letters denote significant differences between yolks (light gray). The significant differences between oil globules (dark gray) are shown using different lowercase letters $(p<0.05)$.

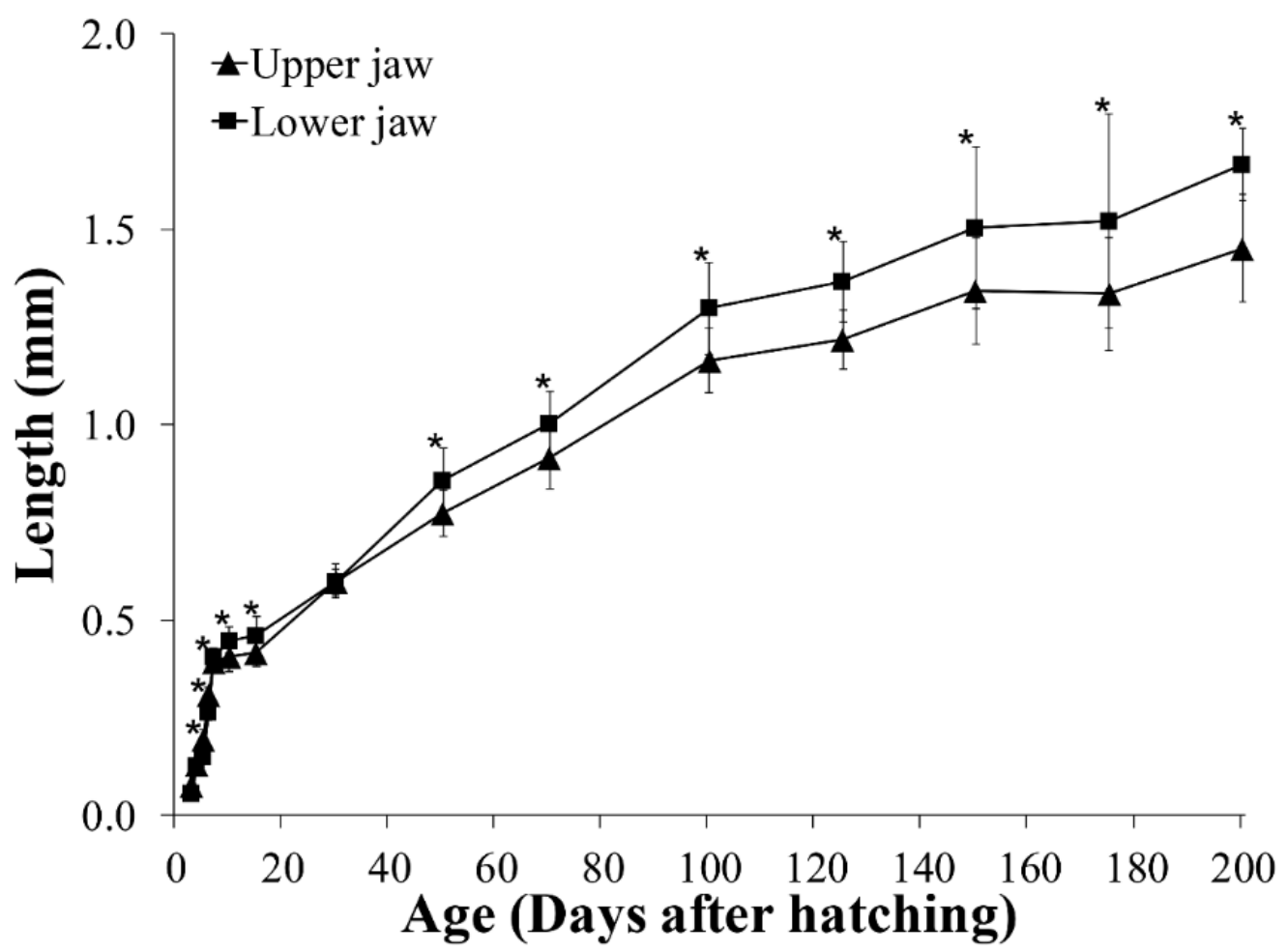

Figure 7. Upper and lower jaw lengths in Anguilla japonica larvae. Values are means \pm SD. Asterisks indicate significant differences between upper and lower jaw lengths $(p<0.05)$. 


\subsubsection{Leptocephalus (Stage III; 40-200 DAH)}

At $50 \mathrm{DAH}$, the average TL was $17.86 \pm 0.82 \mathrm{~mm}$, and most of the melanophores at the tip of the caudal fin had disappeared. The needle-like teeth were replaced by regular broad-based teeth, and a significant difference was observed between upper jaw length $(0.773 \pm 0.058 \mathrm{~mm})$ and lower jaw length $(0.859 \pm 0.081 \mathrm{~mm})(p<0.05)$. The digestive tract length (preanal length) was $14.02 \pm 0.54 \mathrm{~mm}$, and the position of the anus was $78.5 \%$ of the body length. The number of preanal myomeres was 69-73 $(n=5)$, which was greater than at $30 \mathrm{DAH}$. At $100 \mathrm{DAH}$, the average TL was $29.65 \pm 1.75 \mathrm{~mm}$, and digestive tract length (preanal length) was $22.03 \pm 1.36 \mathrm{~mm}$. The anus was located at $74.3 \%$ of the body length, and the number of preanal myomeres was $72-73(n=5)$. At $150 \mathrm{DAH}$, the average TL was $43.07 \pm 3.05 \mathrm{~mm}$, and with the continuous increase in trunk length, the body shape changed to a willow leaf-like form. Digestive tract length (preanal length) was $31.57 \pm 2.19 \mathrm{~mm}$, the anus was located at $73.3 \%$ of the body length, and the number of preanal myomeres was 72-73 $(n=5)$. At $200 \mathrm{DAH}$, the average TL was $52.66 \pm 4.26 \mathrm{~mm}$, and a significant difference between upper jaw length $(1.452 \pm 0.139 \mathrm{~mm})$ and lower jaw length $(1.667 \pm 0.092 \mathrm{~mm})$ was observed continuously from 50 to $200 \mathrm{DAH}(p<0.05)$. Digestive tract length (preanal length) was $38.47 \pm 2.83 \mathrm{~mm}$, the position of the anus decreased to $73.0 \%$ of body length with growth, and the numbers of preanal myomeres was 71-73 $(n=5)$. Therefore, in leptocephalus stage, eel had the characteristic that needle-like teeth were replaced by regular broad-based teeth, the position of the anus moved forward, and the number of preanal myomeres was maintained at 71-73 (Figures 3, 5C and 7).

\subsection{Allometric Growth}

\subsubsection{Larval Stages}

In the yolk sac larval stage, head height and tail parts (length and height) showed positive allometric growth ( $b=1.40, b=2.21$, and $b=1.20$, respectively). However, head length and trunk parts (length and height) showed negative allometric growth $(b=0.83$, $b=0.59$, and $b=-0.16$, respectively) (Figure $8 \mathrm{~A}$ ). In the pre-leptocephalus stage, head parts (length and height) showed negative allometric ( $b=0.62$ and $b=0.65$, respectively), while trunk parts (length and height) showed positive allometric growth $(b=1.32$ and $b=1.16$, respectively). The tail parts showed negative allometric growth in length $(b=0.39)$ and positive allometric growth in height $(b=1.72)$ (Figure $8 \mathrm{~B})$. In the leptocephalus stage, head parts (length and height) showed negative allometric growth $(b=0.71$ and $b=0.68$, respectively). In the trunk parts, length showed nearly isometric growth $(b=0.96)$ and height showed positive allometric growth $(b=1.38)$. Tail parts (length and height) showed positive allometric growth ( $b=1.23$ and $b=1.50$, respectively) (Figure $8 C$ ).

\subsubsection{Body Parts}

Growth of head length was divided into three distinct phases in ontogeny of eel larvae. Phase I showed positive allometric growth during 3.23-5.99 mm TL ( $a=0.117$, $b=1.21, \mathrm{R}^{2}=0.96$ ). In contrast, phase II and showed negative allometric growth with the head decreasing during 5.99-6.75 mm TL $\left(a=7.774, b=-1.15, \mathrm{R}^{2}=0.08\right)$ and during $6.75-60.06 \mathrm{~mm}$ TL $\left(a=0.257, b=0.69, \mathrm{R}^{2}=0.99\right)$, respectively (Figure 9A). Growth of head height was divided into two distinct phases. Phase I involved positive allometric growth during 3.23-7.57 mm TL $\left(a=0.041, b=1.36, \mathrm{R}^{2}=0.89\right)$, while phase II showed negative allometric growth during 7.57-60.06 mm TL ( $\left.a=0.150, b=0.72, \mathrm{R}^{2}=0.98\right)$ (Figure 9B). As a result, head parts showed positive allometric growth in the early stages and the growth pattern then changed to negative allometric growth. Growth of trunk length was divided into three distinct phases. Phase I involved negative allometric growth during 3.23-6.69 mm TL $\left(a=1.215, b=0.57, \mathrm{R}^{2}=0.94\right)$, while phase II showed positive allometric growth during 6.69-10.01 mm TL $\left(a=0.204, b=1.52, \mathrm{R}^{2}=0.86\right)$, and thereafter the growth trend became near isometric during 10.01-60.06 mm TL $(a=0.752, b=0.96$, $\mathrm{R}^{2}=0.99$ ) (Figure 9C). Growth of tail length was divided into two distinct phases. Phase I involved positive allometric growth during 3.23-6.72 $\mathrm{mm} \mathrm{TL}\left(a=0.031, b=2.24, \mathrm{R}^{2}=0.98\right)$, 
while phase II showed near isometric growth during 6.72-60.06 mm TL $(a=0.272, b=0.98$, $R^{2}=0.97$ ) (Figure 9E). Therefore, the lengths of both the tail and trunk showed characteristic near isometric changes. Growth of trunk height was divided into two distinct phases. Phase I showed negative allometric growth during 3.23-6.90 mm TL $(a=0.912, b=-0.15$, $\mathrm{R}^{2}=0.20$ ), while phase II showed positive allometric growth during $6.90-60.06 \mathrm{~mm} T \mathrm{TL}$ $\left(a=0.049, b=1.33, \mathrm{R}^{2}=0.97\right.$ ) (Figure 9D). Growth of tail muscle height was divided into three distinct phases. Phase I showed negative allometric growth during $3.23-5.50 \mathrm{~mm}$ TL ( $\left.a=0.071, b=0.42, \mathrm{R}^{2}=0.40\right)$, while phases II showed positive allometric growth during $5.50-6.43 \mathrm{~mm}$ TL ( $\left.a=0.002, b=2.64, \mathrm{R}^{2}=0.43\right)$, and phase III also showed positive allometric growth during 6.43-60.06 mm TL ( $\left.a=0.014, b=1.47, \mathrm{R}^{2}=0.99\right)$ (Figure 9F). Thus, the heights of both the tail and trunk finally showed positive allometric growth The changes in length and height of the digestive tract were divided into three distinct phases. Digestive tract length showed negative allometric growth during $3.23-6.78 \mathrm{~mm}$ TL ( $\left.a=1.379, b=0.63, \mathrm{R}^{2}=0.96\right)$, positive allometric growth during $6.78-10.01 \mathrm{~mm} \mathrm{TL}$ ( $a=0.301, b=1.44, \mathrm{R}^{2}=0.84$ ), and became near isometric during 10.01-60.06 mm TL ( $a=0.948, b=0.93, \mathrm{R}^{2}=0.99$ ) (Figure 9G). Similarly, digestive tract height showed negative allometric growth during 4.64-6.26 mm TL $\left(a=0.131, b=-0.56, \mathrm{R}^{2}=0.12\right)$, positive allometric growth during 6.26-10.01 mm TL $\left(a=2 \times 10^{-7}, b=6.62, \mathrm{R}^{2}=0.75\right)$, and finally became near isometric during 10.01-60.06 mm TL $\left(a=0.216, b=0.95, \mathrm{R}^{2}=0.92\right)$ (Figure 9H). These observations indicted that the growth patterns of digestive tract parts changed in the order of negative allometric, positive allometric, and isometric growth.

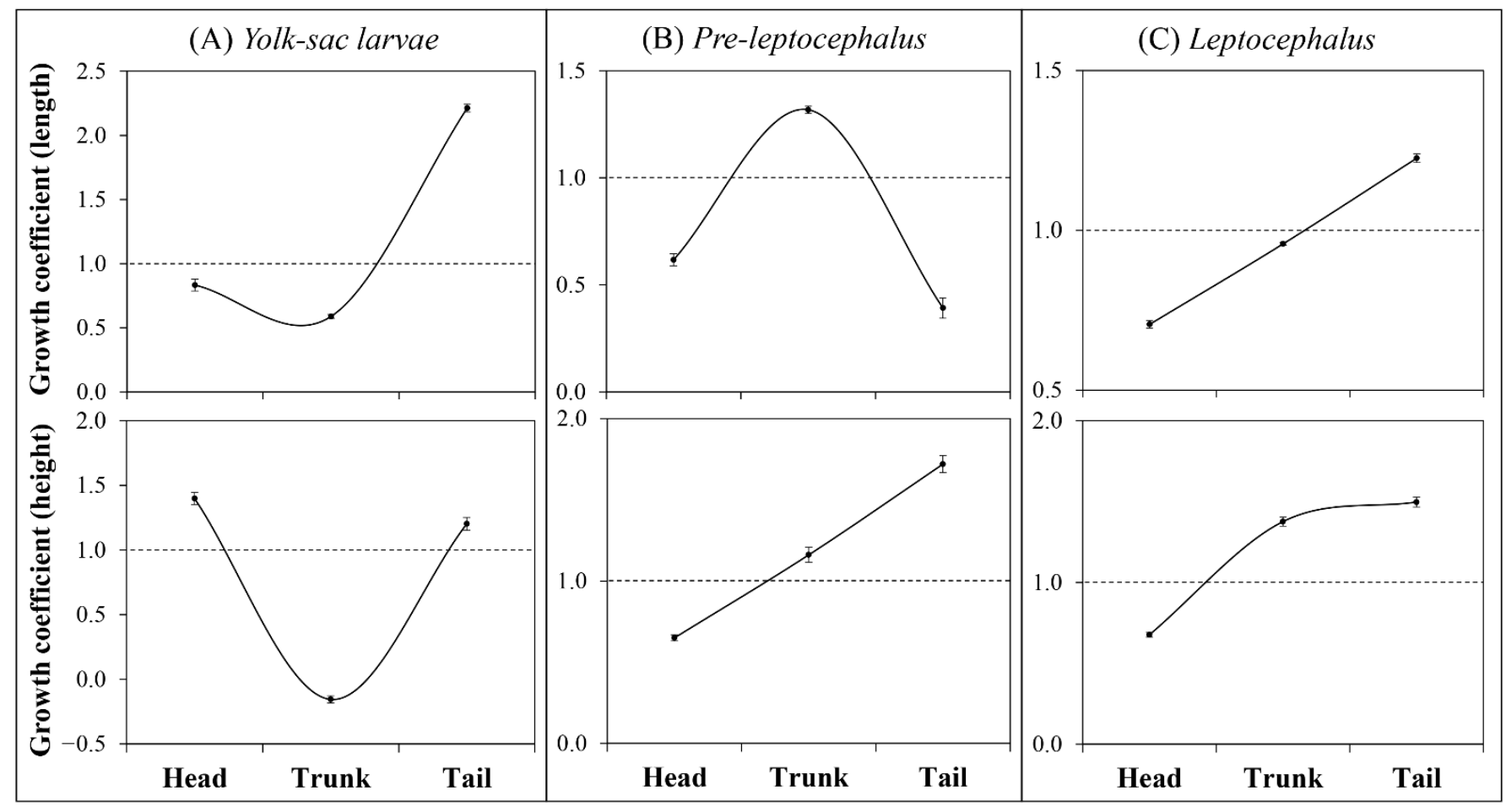

Figure 8. Growth coefficients of head, trunk, and tail parts in larval stages of Anguilla japonica. (A) Yolk sac larval stage: 3.23-6.85 mm TL. (B) Pre-leptocephalus stage: 6.85-15.31 mm TL. (C) Leptocephalus stage: 15.31-60.06 mm TL. Values are means \pm SD. Abbreviation: TL, total length. 

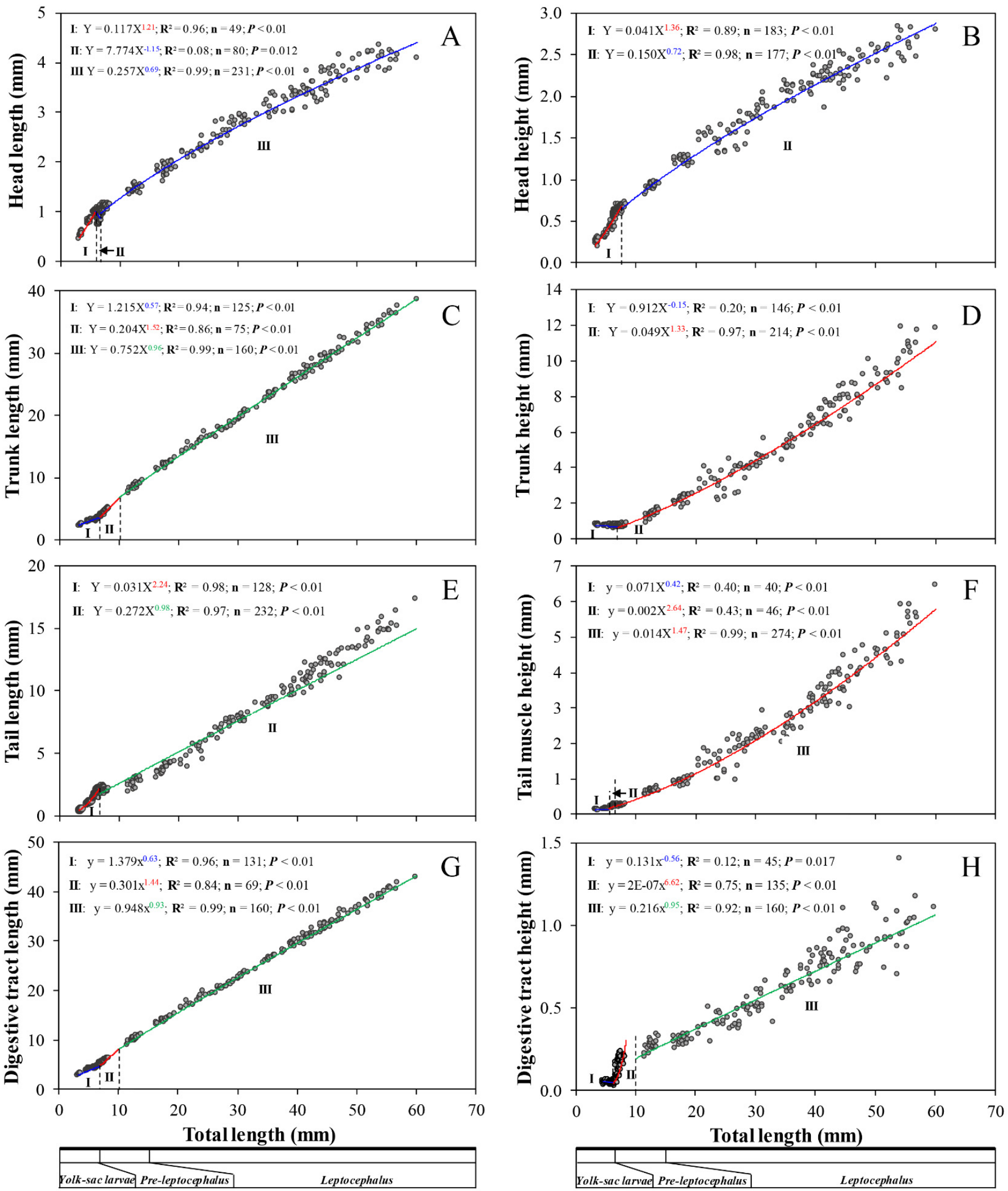

Figure 9. Allometric growth equations between measured body proportions from 0 to $200 \mathrm{DAH}$ in Anguilla japonica larvae. (A) Head length. (B) Head height. (C) Trunk length. (D) Trunk height. (E) Tail length. (F) Tail muscle height. (G) Digestive tract length. (H) Digestive tract height. The dashed lines represent the inflexion points of growth. Abbreviation: DAH, days after hatching. 


\section{Discussion}

The fish larvae stage represents the stage with the highest vulnerability in a fish life cycle [40-42]. Initial mass mortality occurs internally due to the drastic development of organs, including the digestive and swimming organs necessary for the primary nutrient source shifts from endogenous reserve to exogenous feeding [43] and externally due to starvation and predation [44]. Therefore, in order to increase seed production in a culture environment, it is important to provide an optimal rearing protocol with an understanding of the change of internal factors.

In this study, the size of TL that separated the larval stages was similar to the sizes dividing wild eel larval stages reported by Mochioka [27], namely yolk sac larval stage (until approximately $7 \mathrm{~mm}$ ) and pre-leptocephalus stage (until approximately $15 \mathrm{~mm}$ ). However, Mochioka [27] reported that the number of preanal myomeres was maintained at approximately 79 and the position of the anus remained stable in the leptocephalus stage, while in the present study the number of preanal myomeres was maintained at approximately 72 and the anus moved to the anterior of the body. A previous study also reported that the number of preanal myomeres in cultured eel larvae was lower until $100 \mathrm{DAH}$ [30]. Wild eel larvae are known to grow at a rate of $0.5 \mathrm{~mm} /$ day [11,45], while the growth rate of cultured eel larvae in this study $(0.2-0.3 \mathrm{~mm} /$ day $)$ was only half that of wild larvae. Cultured eel larvae were reported previously to show similar growth rates until 100 DAH [30]. Therefore, cultured and wild eel larvae showed differences in the number of preanal myomeres and growth rate, which were thought to be due to artificial maturity, feed, and rearing environment. Further studies of the reasons for these differences are warranted.

In this study, the average yolk sac area after hatching was $0.691 \pm 0.057 \mathrm{~mm}^{2}$. Larvae of the European eel, Anguilla anguilla, which belongs to the same genus as A. japonica, were reported to show a similar yolk sac area of $0.6-0.7 \mathrm{~mm}^{2}$ at $22{ }^{\circ} \mathrm{C}$ [46]. The average oil globule area of $A$. japonica larvae after hatching was $0.086 \pm 0.004 \mathrm{~mm}^{2}$, but increased to $0.107 \pm 0.016 \mathrm{~mm}^{2}$ at $1 \mathrm{DAH}$ in the present study. This was assumed not to be an actual increase in size of the oil globule, but to have been due to the fact that the oil globule was moved to the back as the yolk was rapidly absorbed and was pressed, resulting in an increased measurement. Indeed, at $1 \mathrm{DAH}$, the average yolk sac area had decreased by $39.3 \%$ and the average trunk height had also decreased by $0.043 \mathrm{~mm}$. In this study, the endogenous reserves of eel larvae were mostly absorbed before $7 \mathrm{DAH}$, and the first feeding started at $7 \mathrm{DAH}$, so they had a very short period of mixed feeding or no mixed feeding period. The mixed feeding period is a period with the simultaneous consumption of endogenous and exogenous feeding [47], which helps the growth and survival of the larvae by temporary nutritional supplementation during the transition to exclusively exogenous feeding and prevents nutritional deficiencies during starvation [48]. In some teleost fishes, including the tiger grouper (Epinephelus fuscoguttatus), Asian sea bass (Lates calcarifer), and olive flounder (Paralichthys olivaceus), short starvation or immediate feeding after the completion of endogenous reserve absorption has been shown to result in better growth and survival [49-51]. Therefore, eel larvae may also show increased growth and survival if fed at the optimal initial feeding time. In particular, as starvation can easily occur in eel larvae due to the characteristics of the slurry-type diet under culture rearing conditions [52], good management and appropriate rearing protocols specific to eel are necessary.

As shown in Figure 1A, numerous eel larvae feeding on the slurry-type diet with the posteriorly bent lower jaw were observed in the leptocephalus stage. This abnormality was thought to be due to elongation of the lower jaw and increased swimming ability with growth during the process of feeding the slurry-type diet supplied at the bottom of the tank. Indeed, from $50 \mathrm{DAH}$, there was a continuous significant difference between the average length of the upper jaw and the lower jaw $(p<0.05)$, and at $50 \mathrm{DAH}$, the length of the lower jaw was longer by only $0.088 \mathrm{~mm}$, but the difference increased with growth, and it became longer by $0.215 \mathrm{~mm}$ at $200 \mathrm{DAH}$. These eel larvae with lower jaw deformity showed similar growth and survival compared to normal larvae during the larval stage feeding 
the slurry-type diet, but they did not survive longer since they were fed with the pellet or paste-type diet after metamorphosis into glass eels (juveniles). Therefore, to prevent deformity of the lower jaw of eel larvae, it is necessary to develop a new non-slurry-type diet suitable for the leptocephalus stage.

Allometry is related to the chronology of important early life history events [24]. Larvae adjust the development rate of certain structures according to the physiological priorities of the species for survival [53]. In general, allometric growth of larval body regions shows a U-shaped growth profile (i.e., allometric growth of head and tail regions exhibiting higher growth rates compared to the trunk region) during the endogenous feeding period $[21,24,25,54-56]$. In this study, in the yolk sac larval stage, allometric growth of the larval head parts (length and height) showed a U-shaped growth profile. This growth pattern could be interpreted as an adaptive strategy to reduce and optimize the energy cost of larval transport [22,56,57]. During the early larval stage, the head parts commonly exhibited positive allometric growth, which is an early developmental strategy of teleost fish to give priority to development of the brain, respiratory, sensory, and feeding organs $[24-26,54,55]$. In this study, head length showed negative allometric growth $(b=0.83)$ in the yolk sac larval stage. Indeed, head length of eel larvae showed positive allometric growth $(b=1.21)$ from hatching to $5.99 \mathrm{~mm}$ TL (approx. $2 \mathrm{DAH})$, which then changed to negative allometric growth $(b=-1.15)$. This growth pattern of head length was thought to be due to the change in position of the top of head. The top of the head of eel larvae faces forward at hatching. However, with the development of the lower jaw, the top of the head gradually changes to face upward, so eel larvae measurements appear to show a decrease in head length from $3 \mathrm{DAH}(1.003 \pm 0.035 \mathrm{~mm})$ to $6 \mathrm{DAH}(0.767 \pm 0.031 \mathrm{~mm})$. Therefore, eel larvae are considered to have advantages in the brain, respiratory, sensory, and feeding organs with prioritization of the development of head parts, similar to the early developmental strategy of teleost fish. On the other hand, eel larval head parts (length and height) continued to show negative allometric growth. In many teleost species, the pattern of allometric growth tends to change to isometric growth during transformation to the juvenile stage [21,57]. However, the head parts of eel larvae maintained negative allometric growth until before metamorphosis stage, which was assumed to be related to maintenance of the willow leaf-like body shape of eel larvae.

In general, the growth pattern of eel larval trunk parts is thought to be related to the digestive system, but as eel larvae have a straight rather than a coiled gut, it would be more reasonable to understand in terms of body shape change than in relation to the digestive system. In this study, in the yolk sac larval stage, trunk parts (length and height) showed negative allometric growth and tail parts (length and height) showed positive allometric growth, similar to a U-shaped growth profile of general teleost species. Subsequently, in the pre-leptocephalus stage, trunk length changed to show positive allometric growth $(b=1.318)$ and tail length to negative allometric growth $(b=0.392)$. However, as the fiducial line of the trunk and tail is divided at the position of the anus, this change in growth pattern was considered to be a measurement error due to the change in position of the anus with growth. Indeed, as the position of the anus tends to move posteriorly in eel larvae during the pre-leptocephalus stage and to move anteriorly during the leptocephalus stage, it would be appropriate to check the allometric growth of trunk and tail in terms of height rather than length to understand the growth characteristics of eel larvae.

In terms of height, both the trunk and tail showed positive allometric growth in the pre-leptocephalus stage and leptocephalus stage. In addition, when the inflection point of the allometric growth pattern was confirmed, trunk height showed negative allometric growth $(b=-0.15)$ due to the decrease of yolk until $6.900 \mathrm{TL} \mathrm{mm}(6-7 \mathrm{DAH})$, and then showed positive allometric growth until the end of the experiment. Tail muscle height showed negative allometric growth $(b=0.42)$ up to $5.501 \mathrm{~mm}$ TL $(1-2 \mathrm{DAH})$, with rare swimming but high positive allometric growth $(b=2.64)$ until $6.425 \mathrm{~mm} \mathrm{TL}$ (approx. $4 \mathrm{DAH}$ ) before the first feeding. Thereafter, continuous positive allometric growth $(b=1.47)$ was observed until the end of the experiment. As mentioned above, allometric growth of the 
larvae of teleost species becomes close to isometric growth with growth to the juvenile stage, but eel larvae showed continuous positive allometric growth in trunk and tail height and continuous negative growth in their head parts. These growth patterns were assumed to reflect the unique early life history of eels. The eel has a unique willow leaf-like form during its early life history, and these growth patterns of eel larvae were also thought to be related to the body shape. The willow leaf-like form body of leptocephalus is suitable for long distance dispersal by currents [1], and may have been adapted to the characteristics of the early ecology involving migration over long distances. Positive allometric growth of tail muscle height is known to contribute to improvement of swimming ability [26]. As A. japonica leptocephali is known to have a diel vertical migration, staying at $100 \mathrm{~m}$ at night and migrating deeper during the daytime [58]. Most leptocephali species with visible gut contents appear to be more frequently caught during the day and crepuscular periods $[59,60]$, which may be a strategy to facilitate digestion and assimilation of food and growth in the warmer water after feeding occurs in deeper layers [61-63]. So, the positive allometric growth of tail muscle height is thought to reflect the early ecology of eels. Overall, these growth patterns of trunk height, tail muscle height, and head parts may be adaptive characteristics for the unique early life history of $A$. japonica.

In this study, the digestive tract parts (length and height) of eel larvae showed similar allometric growth patterns. Digestive tract height showed negative allometric growth $(b=-0.56)$ from hatching to $6.26 \mathrm{~mm}$ TL (2-3 DAH), followed by a sharp change to positive allometric growth $(b=6.62)$ until $10.01 \mathrm{~mm}$ TL $(15-30 \mathrm{DAH})$. Digestive tract length showed negative allometric growth $(b=0.63)$ from hatching to $6.78 \mathrm{~mm}$ TL (6-7 DAH, before first feeding), and then positive allometric growth $(b=1.44)$ until $10.01 \mathrm{~mm}$ (15-30 DAH). This change in positive allometric growth in these digestive tract parts may be advantageous in terms of consuming more food at first feeding. Indeed, the average area of intestine decreased at $6 \mathrm{DAH}\left(0.103 \pm 0.015 \mathrm{~mm}^{2}\right)$ compared to $5 \mathrm{DAH}$ $\left(0.122 \pm 0.019 \mathrm{~mm}^{2}\right)$, but increased sharply from $7 \mathrm{DAH}\left(0.127 \pm 0.007 \mathrm{~mm}^{2}\right.$ at first feeding to $30 \mathrm{DAH}\left(1.022 \pm 0.189 \mathrm{~mm}^{2}\right)$. Thereafter, digestive tract length and height changed from $10.01 \mathrm{~mm}$ TL (15-30 DAH) to close to isometric growth $(b=0.93, b=0.95$, respectively). A change to isometry in allometric growth patterns of teleost species during the early development stages has been interpreted as completion of the development of some of the primary physiological systems with the formation and maturation of several sensory and digestive organs $[25,26,53]$. Indeed, Shin et al. [64] reported that the histological differentiation of digestive organs of eel larvae was mostly completed by $15 \mathrm{DAH}$, and Shin et al. [65] found that digestive enzyme activity of eel larvae increased rapidly until $30 \mathrm{DAH}$. In other words, eel larvae show rapid development of the function and differentiation of the digestive system before $30 \mathrm{DAH}$, these rapid changes in the digestive system may be related to critical period I, II that occur at the same time. Hsu et al. [20] reported that the slurry-type diet is difficult to digest and absorb in the eel larval intestine. Therefore, eel larvae should be necessary to develop the optimal diets suitable for the ontogeny of digestive ability before $30 \mathrm{DAH}$.

\section{Conclusions}

This study was performed to determine the changes in morphology and growth pattern during eel larval stages. When cultured eel larvae were divided according to the morphological criteria of wild eel larvae, the sizes of TL that divided the stages were similar between cultured and wild eel larvae. However, cultured eel larvae differed from wild eel larvae in terms of growth rate and the number of preanal myomeres. These differences suggest that further advances are still needed in cultured eel seed rearing techniques. In particular, as eel larvae, which rarely have mixed feeding periods, do not feed immediately after mouth opening, further research is required to determine the optimal first feeding time. In addition, the lower jaw abnormality of eel larvae was assumed to be caused by the slurrytype diet supplied at the bottom of the tank, and a new diet should be developed for the leptocephalus stage (wherein the lower jaw is longer than the upper jaw). Meanwhile, the 
relative growth pattern of the body parts changed only before $30 \mathrm{DAH}$, and mass mortality appeared at this time. In particular, the allometric growth of digestive tract parts fluctuated rapidly during this period, consistent with histological and physiological events during the ontogeny of eel larvae. Therefore, to improve the growth and survival rate of cultured eel larvae, studies should focus on developing an optimal feeding and rearing protocol from the first feeding to $30 \mathrm{DAH}$. This study provided baseline information for understanding the early life history and improving optimal rearing protocols of freshwater eels.

Author Contributions: Conceptualization, Y.-W.R., Y.-H.C. and S.-K.K.; funding acquisition, S.-K.K.; investigation, writing—original draft, M.-G.S.; writing—review and editing, Y.-H.C. and S.-K.K.; supervision, Y.-H.C. and S.-K.K. All authors have read and agreed to the published version of the manuscript.

Funding: This work was supported by a grant from the National Institute of Fisheries Science, Korea (R2022011).

Institutional Review Board Statement: Not applicable.

Informed Consent Statement: Not applicable.

Data Availability Statement: Not applicable.

Acknowledgments: We thank the eel research team of the National Institute of Fisheries Science for technical support on fish rearing.

Conflicts of Interest: The authors declare no conflict of interest.

\section{References}

1. Cheng, P.W.; Tzeng, W.N. Timing of metamorphosis and estuarine arrival across the dispersal range of the Japanese eel Anguilla japonica. Mar. Ecol. Prog. Ser. 1996, 131, 87-96. [CrossRef]

2. Kuroki, M.; Aoyama, J.; Miller, M.J.; Yoshinaga, T.; Shinoda, A.; Hagihara, S.; Tsukamoto, K. Sympatric spawning of Anguilla marmorata and Anguilla japonica in the western North Pacific Ocean. J. Fish Biol. 2009, 74, 1853-1865. [CrossRef]

3. Tesch, F.W. Developmental stages and distribution of the eel species. In The Eel, 3rd ed.; Thorpe, J.E., Ed.; Blackwell Science Ltd.: Oxford, UK, 2003; pp. 73-118.

4. Tsukamoto, K.; Aoyama, J.; Miller, M.J. Present status of the Japanese eel: Resources and recent research. in Eels at the edge: Sicence, status, and conservation concern. Am. Fish. Soc. Symp. 2009, 58, 21-35.

5. Hibiya, T. Success in collecting fully matured eel eggs. Aquac. (Yos+hoku) 1970, 3, 12-15.

6. Yamamoto, K.; Yamauchi, K. Sexual maturation of Japanese eel and production of eel larvae in the aquarium. Nature 1974, 251, 220-222. [CrossRef]

7. Tanaka, H.; Kagawa, H.; Ohta, H.; Unuma, T.; Nomura, K. The first production of glass eel in captivity: Fish reproductive physiology facilitates great progress in aquaculture. Fish Physiol. Biochem. 2003, 28, 493-497. [CrossRef]

8. Ijiri, S.; Tsukamoto, K.; Chow, S.; Kurogi, H.; Adachi, S.; Tanaka, H. Controlled reproduction in the Japanese eel (Anguilla japonica), past and present. Aquac. Eur. 2011, 36, 13-17. Available online: http://hdl.handle.net/2115/47268 (accessed on 12 December 2021).

9. Masuda, Y.; Imaizumi, H.; Usuki, H.; Oda, K.; Hashimoto, H.; Teruya, K. Artificial completion of the Japanese eel, Anguilla japonica, life cycle: Challenge to mass production. Bull. Fish Res. Agency 2012, 35, 111-117.

10. Tanaka, H. Progression in artificial seedling production of Japanese eel Anguilla japonica. Fish. Sci. 2015, 81, 11-19. [CrossRef]

11. Okamura, A.; Horie, N.; Mikawa, N.; Yamada, Y.; Tsukamoto, K. Recent advances in artificial production of glass eels for conservation of anguillid eel population. Ecol. Freshw. Fish 2014, 23, 95-110. [CrossRef]

12. Okamura, A.; Yamada, Y.; Horita, T.; Horie, N.; Mikawa, N.; Utoh, T.; Tanaka, S.; Tsukamoto, K. Rearing eel leptocephali (Anguilla japonica Temminck \& Schlegel) in a planktonkreisel. Aquac. Res. 2009, 40, 509-512. [CrossRef]

13. Tsukamoto, K.; Chow, S.; Otake, T.; Kurogi, H.; Mochioka, N.; Miller, M.J.; Aoyama, J.; Kimura, S.; Watanabe, S.; Yoshinaga, T.; et al. Oceanic spawning ecology of freshwater eels in the western north Pacific. Nat. Commun. 2011, 2, 179. [CrossRef]

14. Otake, T.; Nogami, K.; Maruyama, K. Dissolved and particulate organic matter as possible food sources for eel leptocephali. Mar. Ecol. Prog. Ser. 1993, 92, 27-34. Available online: https://www.jstor.org/stable/24832613 (accessed on 26 December 2021). [CrossRef]

15. Tsukamoto, K.; Miller, M.J. The mysterious feeding ecology of leptocephali: A unique strategy of consuming marine snow materials. Fish. Sci. 2021, 87, 11-29. [CrossRef]

16. Westerberg, H. A proposal regarding the source of nutrition of leptocephalus larvae. Int. Rev. Ges. Hydrobiol. 1990, 75, 863-864. [CrossRef] 
17. Shinoda, A.; Aoyama, J.; Miller, M.J.; Otake, T.; Mochioka, N.; Watanabe, S.; Minegishi, Y.; Kuroki, M.; Yoshinaga, T.; Yokouchi, K.; et al. Evaluation of the larval distribution and migration of the Japanese eel in the western North Pacific. Rev. Fish Biol. Fish. 2011, 21, 591-611. [CrossRef]

18. Kawakami, Y.; Mochioka, N.; Nakazono, A. Immigration period and age of Anguilla japonica glass-eels entering rivers in northern Kyushu, Japan during 1994. Fish. Sci. 1998, 64, 235-239. [CrossRef]

19. Tabeta, O.; Tanaka, K.; Yamada, J.; Tzeng, W.N. Aspects of the early life history of the Japanese eel Anguilla japonica determined from otolith microstructure. Nippon Suisan Gakkaishi 1987, 53, 1727-1734. [CrossRef]

20. Hsu, H.Y.; Chen, S.H.; Cha, Y.R.; Tsukamoto, K.; Lin, C.Y.; Han, Y.S. De Novo assembly of the whole transcriptome of the wild embryo, preleptocephalus, Leptocephalus, and glass eel of Anguilla japonica and deciphering the digestive and absorptive capacities during early development. PLOS ONE 2015, 10, e0139105. [CrossRef]

21. Fuiman, L.A. Growth gradients in fish larvae. J. Fish Biol. 1983, 23, 117-123. [CrossRef]

22. Osse, J.W.M.; van den Boogaart, J.G.M. Fish larvae, development, allometric growth, and the aquatic environment. ICES Mar. Sci. Symp. 1995, 201, 21-34.

23. Çelik, İ.; Çelik, P.; Cirik, S..; Gürkan, M.; Hayretdağ, S. Embryonic and larval development of black skirt tetra (Gymnocorymbus ternetzi, Boulenger, 1895) under laboratory conditions. Aquac. Res. 2012, 43, 1260-1275. [CrossRef]

24. Gisbert, E. Early development and allometric growth patterns in Siberian sturgeon and their ecological significance. J. Fish Biol. 1999, 54, 852-862. [CrossRef]

25. Koumoundouros, G.; Divanach, P.; Kentouri, M. Ontogeny and allometric plasticity of Dentex dentex (Osteichthyes: Sparidae) in rearing conditions. Mar. Biol. 1999, 135, 561-572. [CrossRef]

26. Peña, R.; Dumas, S. Development and allometric growth patterns durng early larval stage of the spotted sand bass Paralabrax maculatofasciatus (Percoidei: Serranidae). Sci. Mar. 2009, 73S1, 183-189. [CrossRef]

27. Mochioka, N. Leptocephali. In Eel Biology; Aida, K., Tsukamoto, K., Yamauchi, K., Eds.; Springer: Tokyo, Japan, 2003; pp. 51-60

28. Yoshimatsu, T. Early development of preleptocephalus larvae of the Japanese eel in captivity with special reference to the organs for larval feeding. Bull. Grad. Sch. Bioresour. Mie Univ. 2011, 37, 11-18.

29. Kim, D.J.; Kang, E.J.; Bae, J.Y.; Park, M.W.; Kim, E.O. Development of the eggs and pre-leptocephalus larvae by natural spawning of artificially-matured japanese eel, Anguilla japonica. J. Aquac. 2007, 20, 160-167.

30. Tanaka, H.; Kagawa, H.; Ohta, H. Production of leptocephali of Japanese eel (Anguilla japonica) in captivity. Aquaculture 2001, 201, 55-60. [CrossRef]

31. Tsukamoto, K.; Yamada, Y.; Okamura, A.; Kaneko, T.; Tanaka, H.; Miller, M.J.; Horie, N.; Mikawa, N.; Utoh, T.; Tanaka, S. Positive buoyancy in eel leptocephali: An adaptation for life in the ocean surface layer. Mar. Biol. 2009, 156, 835-846. [CrossRef]

32. Okamura, A.; Yamada, Y.; Mikawa, N.; Horie, N.; Utoh, T.; Kaneko, T.; Tanaka, S.; Tsukamoto, K. Growth and survival of leptocephali (Anguilla japonica) in low-salinity water. Aquaculture 2009, 296, 367-372. [CrossRef]

33. Okamura, A.; Yamada, Y.; Horie, N.; Mikawa, N.; Tsukamoto, K. Long-term rearing of Japanese eel larvae using a liquid-type diet: Food intake, survival and growth. Fish. Sci. 2019, 85, 687-694. [CrossRef]

34. Kuroki, M.; Fukuda, N.; Yamada, Y.; Okamura, A.; Tsukamoto, K. Morphological changes and otolith growth during metamorphosis of Japanese eel leptocephali in captivity. Coast. Mar. Sci. 2010, 34, 31-38.

35. Okamura, A.; Yamada, Y.; Mikawa, N.; Horie, N.; Tsukamoto, K. Effect of starvation, body size, and temperature on the onset of metamorphosis in Japanese eel (Anguilla japonica). Can. J. Zool. 2012, 90, 1378-1385. [CrossRef]

36. Sudo, R.; Okamura, A.; Kuroki, M.; Tsukamoto, K. Changes in the role of the thyroid axis during metamorphosis of the Japanese eel, Anguilla japonica. J. Exp. Zool. Part A 2014, 321, 357-364. [CrossRef]

37. Kim, S.K.; Lee, B.I.; Kim, D.J.; Lee, N.S. Development of slurry type diet for the growing Leptocephalus, eel larvae (Anguilla japonica). JFMSE 2014, 26, 1209-1216. [CrossRef]

38. Choo, K.C.; Liew, H.C. Morphological development and allometric growth patterns in the juvenile seahorse Hippocampus kuda Bleeker. J. Fish Biol. 2006, 69, 426-445. [CrossRef]

39. Zar, J.H. Comparing simple linear regression equations. In Biostatistical Analysis; Zar, J.H., Ed.; Pearson Education Ltd.: Harlow, UK, 2014; pp. 387-391.

40. O'connell, C.P. Histological criteria for diagnosing the starving condition in early post yolk sac larvae of the northern anchovy, Engraulis mordax Girard. J. Exp. Mar. Biol. Ecol. 1976, 25, 285-312. [CrossRef]

41. Strüssmann, C.A.; Takashima, F. Hepatocyte nuclear size and nutritional condition of starved pejerrey, Odontesthes bonariensis (Cuvier et Valenciennes). J. Fish Biol. 1990, 36, 59-65. [CrossRef]

42. Theilacker, G.H. Effect of starvation on the histological and morphological characteristics of jack mackerel, Trachurus symmetricus, larvae. Fish. Bull. 1978, 76, 403-414.

43. Shin, M.G.; Lee, S.G.; Lee, J.T.; Gwak, W.S. Comparative early developments in winter spawned three pre-larval fishes (Gadus macrocephalus, Liparis tanakae, Hexagrammos agrammus). Korean J. Ichthyol. 2018, 1, 9-17. [CrossRef]

44. Yin, M.C.; Blaxter, J.H.S. Escape speeds of marine fish larvae during early development and starvation. Mar. Biol. 1987, 96, 459-468. [CrossRef]

45. Ishikawa, S.; Suzuki, K.; Inagaki, T.; Watanabe, S.; Kimura, Y.; Okamura, A.; Otake, T.; Mochioka, N.; Suzuki, Y.; Hasumoto, H.; et al. Spawning time and place of the Japanese eel Anguilla japonica in the North Equatorial Current of the western North Pacific Ocean. Fish. Sci. 2001, 67, 1097-1103. [CrossRef] 
46. Politis, S.N.; Mazurais, D.; Servili, A.; Zambonino-Infante, J.L.; Miest, J.J.; Sørensen, S.R.; Tomkiewicz, J.; Butts, I.A.E. Temperature effects on gene expression and morphological development of European eel, Anguilla anguilla larvae. PLoS ONE 2017, 12, e0182726. [CrossRef]

47. Fhyn, H.J. First feeding of marine fish larvae: Are free amino acids the source of energy? Aquaculture 1989, 80, 111-120. [CrossRef]

48. Treviño, L.; Álvarez-González, C.A.; Perales-García, N.; Arévalo-Galán, L.; Uscanga-Martínez, A.; Márquez-Couturier, G.; Fernández, I.; Gisbert, E. A histological study of the organogenesis of the digestive system in bay snook Petenia splendida Günther, 1862 from hatching to the juvenile stage. J. Appl. Ichthyol. 2011, 27, 73-82. [CrossRef]

49. Ching, F.F.; Nakagawa, Y.; Kato, K.; Murata, O.; Miyashita, S. Effects of delayed first feeding on the survival and growth of tiger grouper, Epinephelus fuscoguttatus (Forsskål, 1775), larvae. Aquac. Res. 2012, 4, 303-310. [CrossRef]

50. Kailasam, M.; Thirunavukkarasu, A.R.; Selvaraj, S.; Stalin, P. Effect of delayed initial feeding on growth and survival of Asian sea bass Lates calcarifer (Bloch) larvae. Aquaculture 2007, 271, 298-306. [CrossRef]

51. Dou, S.Z.; Masuda, R.; Tanaka, M.; Tsukamoto, K. Effects of temperature and delayed initial feeding on the survival and growth of Japanese flounder larvae. J. Fish Biol. 2005, 66, 362-377. [CrossRef]

52. Yamada, Y.; Okamura, A.; Mikawa, N.; Horie, N.; Tsukamoto, K. A new liquid-type diet for leptocephali in mass production of artificial glass eels. Fish. Sci. 2019, 85, 545-551. [CrossRef]

53. Martínez-Montaño, E.; González-Álvarez, K.; Lazo, J.P.; Audelo-Naranjo, J.M.; Vélez-Medel, A. Morphological development and allometric growth of yellowtail kingfish Seriola lalandi V. larvae under culture conditions. Aquac. Res. 2016, 47, 1277-1287. [CrossRef]

54. Gisbert, E.; Merino, G.; Muguet, J.B.; Bush, D.; Piedrahita, R.H.; Conklin, D.E. Morphological development and allometric growth patterns in hatchery reared California halibut larvae. J. Fish Biol. 2002, 61, 1217-1229. [CrossRef]

55. Osse, J.W.M.; Van den Boogaart, J.G.M.; Van Snik, G.M.J.; Van der Sluys, L. Priorities during early growth of fish larvae. Aquaculture 1997, 155, 249-258. [CrossRef]

56. Van Snik, G.M.J.; van den Boogaart, J.G.M.; Osse, W.M. Larval growth patterns in Cyprinus carpio and Clarias gariepinus with attention to the finfold. J. Fish Biol. 1997, 50, 1339-1352. [CrossRef]

57. Osse, J.W.M.; van den Boogaart, J.G.M. Allometric growth in fish larvae: Timing and function. Am. Fish. Soc. Symp. 2004, 40, 167-194.

58. Otake, T.; Miller, M.J.; Inagaki, T.; Minagawa, G.; Shinoda, A.; Kumura, Y.; Sasai, S.; Oya, M.; Tasumi, S.; Suzuki, Y.; et al. Evidence for migration of metamorphosing larvae of Anguilla japonica in the Kuroshio. Coast. Mar. Sci. 2006, 30, 453-458. Available online: https:/ / agris.fao.org/agris-search/search.do?recordID=AV20120103567 (accessed on 22 January 2022).

59. Miller, M.J.; Otake, T.; Aoyama, J.; Wouthuyzen, S.; Suharti, S.; Sugeha, H.Y.; Tsukamoto, K. Observations of gut contents of leptocephali in the North Equatorial Current and Tomini Bay, Indonesia. Coast. Mar. Sci. 2011, 35, $277-288$.

60. Miller, M.J.; Marohn, L.; Wysujack, K.; Freese, M.; Pohlmann, J.D.; Westerberg, H.; Tsukamoto, K.; Hanel, R. Morphology and gut contents of anguillid and marine eel larvae in the Sargasso Sea. Zool. Anz. 2019, 279, 138-151. [CrossRef]

61. Miller, M.J. Ecology of anguilliform leptocephali: Remarkable transparent fish larvae of the ocean surface layer. Aqua-BioSci. Monogr. 2009, 2, 1-94. [CrossRef]

62. Miller, M.J. Nighttime vertical distribution and regional species composition of eel larvae in the western Sargasso Sea. Reg. Stud. Mar. Sci. 2015, 1, 34-46. [CrossRef]

63. Onda, H.; Miller, M.J.; Takeshige, A.; Miyake, Y.; Kuroki, M.; Aoyama, J.; Kimura, S. Vertical distribution and assemblage structure of leptocephali in the North Equatorial Current region of the western Pacific. Mar. Ecol. Prog. Ser. 2017, 575, 119-136. [CrossRef]

64. Shin, M.G.; Kim, S.K.; Lee, B.I.; Choi, Y.H.; Ryu, Y. Histological development of the digestive system in artificially produced Anguilla japonica larvae. Korean J. Fish. Aquat. Sci. 2021, 54, 298-310. [CrossRef]

65. Shin, M.G.; Ryu, Y.; Choi, Y.H.; Kim, S.K. Ontogeny in the digestive and absorptive capacities of Anguilla japonica larvae. In Proceedings of the ISFNF International Symposium on Fish Nutrition and Feeding, Busan, Korea, 12-16 December 2021. 